\title{
Aconselhamento em HIV/AIDS: pressupostos teóricos para uma prática clínica fundamentada
}

\author{
Counseling on HIVIAIDS: theoretical background for an evidence based clinical practice \\ Asesoramiento en VIH/SIDA: premisas teóricas para una práctica clínica fundamentada
}

\section{Clarisse Sampaio Pequeno', Simara Moreira de Macêdo", Karla Corrêa Lima Miranda"I}

' Universidade Estadual do Ceará, Curso de Graduação em Enfermagem (Graduanda). Fortaleza-CE, Brasil.

"Universidade Estadual do Ceará, Programa de Pós-Graduação em Cuidados Clínicos em Enfermagem e Saúde (Mestranda). Fortaleza-CE, Brasil

I"I Universidade Estadual do Ceará, Curso de Graduação em Enfermagem, Programa de Pós-Graduação em Cuidados Clínicos em Enfermagem e Saúde. Fortaleza-CE, Brasil.

Submissão: 05-08-2011 Aprovação: 21-05-2013

\section{RESUMO}

Com o avanço da AIDS no Brasil, o Ministério da Saúde sentiu a necessidade de sensibilizar e treinar profissionais de saúde para trabalhar com questões provocadas pela infecção ou pela doença. Neste sentido, surgiu a implantação de centros de orientação e apoio sorológico (CTA), que passaram a ser a principal referência em aconselhamento. O aconselhamento em HIV/AIDS é um dispositivo utilizado por profissionais de saúde buscando trabalhar informação, orientação, avaliação de risco e apoio na realização da sorologia anti-HIV. Entretanto, faz-se necessário que esta estratégia tenha fundamentos teórico-filosóficos que sirvam para embasar a prática clínica do aconselhador. Logo, este artigo objetivou apresentar os principais pressupostos de algumas teorias do aconselhamento psicológico e sua relação com a prática do aconselhamento em HIV/AIDS. Acredita-se que estas reflexões poderão contribuir para fundamentar teoricamente os profissionais que realizam aconselhamento em HIV/AIDS, configurando-o realmente em um dispositivo para promoção da saúde.

Descritores: Aconselhamento; Síndrome de Imunodeficiência Adquirida; Teoria Psicológica.

\begin{abstract}
As AIDS advances in Brazil, the Ministry of Health felt the need to sensitize and to train health professionals to work with questions provoked by this infection or by the disease. The implantation of counseling centers and support serological support (CTA) arose and became the main reference in counseling. The HIV / AIDS counseling is a device used by health professionals seeking to work information, guidance, risk assessment and support in accomplish the anti-HIV serology. However, it is necessary that this strategy have theoretical and philosophical fundaments that serve to underpin the counselor's clinical practice. Therefore, this article aimed to present the main presuppositions of some psychological counseling theories and its relation to the practice of HIV/AIDS counseling. It is believed that these reflections can contribute to substantiate theoretically the professionals who perform HIV/AIDS counseling, configuring it as a device for health promotion.
\end{abstract}

Key words: Counseling; Acquired Immunodeficiency Syndrome; Psychological Theory.

\section{RESUMEN}

Con el avanzo del SIDA en Brasil, el Ministerio de Salud ha percibido la necesidad de sensibilizar y capacitar profesionales de salud para trabajar con los aspectos referentes a la infección o la enfermedad. Así, se creó los Centros de Pruebas y Apoyo serológico (CTA), que son la principal referencia en aconsejamiento. La aconsejamiento en VIH/SIDA es una intervención utilizada por profesionales de salud que objetiva proporcionar información, orientación, evaluación de riesgo y apoyo en la realización de la prueba de detección del VIH. Sin embargo, es necesario basar la práctica clínica del profesional que hace la aconsejamiento. Por lo tanto, esta investigación tuvo como objetivo presentar las principales premisas de algunas teorías del aconsejamiento psicológico y su relación con la práctica de aconsejamiento en VIH/SIDA. Se cree que estas reflexiones podrán contribuir para fundamentar de modo teórico los profesionales que realizan aconsejamiento en VH/SIDA, tornándolo, en seguida, una intervención para la promoción de la salud.

Palabras clave: Aconsejamiento; Síndrome de Inmunodeficiencia Adquirida; Teoría Psicológica. 


\section{INTRODUÇÃO}

O termo aconselhamento foi usado, tradicionalmente, em conexão a situações como fornecer informações, dar conselhos, criticar, encorajar, apresentar sugestões e interpretar o cliente e o significado de seu comportamento. Enquanto prática, o aconselhamento foi desenvolvido, inicialmente, nos Estados Unidos, no princípio do século XX, como um dispositivo da assistência social, oferecendo apoio a problemas financeiros, oportunidades de expressão e alívio das tensões e angústias. Entretanto, à medida que as suas técnicas tornaram-se mais elaboradas e a sua aplicação ampliada através da utilização de teorias científicas, as definições de aconselhamento sofreram idênticas evoluções, transformando-se em um ramo da psicologia(1-2).

No âmbito HIV/AIDS, o termo aconselhamento surgiu como uma estratégia elaborada pela equipe nacional do Ministério da Saúde para se trabalhar com HIV/AIDS, caracterizando-se por ser uma estratégia de prevenção que atua no âmbito do indivíduo, de forma a trabalhar com a identificação do próprio risco e propiciar uma reflexão sobre medidas preventivas viáveis para o indivíduo que deseja realizar a sorologia anti-HIV, tendo como componentes o apoio emocional, o apoio educativo que trata das trocas de informações sobre DST e HIV/AIDS, suas formas de transmissão, prevenção, tratamento e avaliação de $\operatorname{riscos}^{(3)}$.

No Brasil, a primeira experiência oficial de orientação sobre modos de prevenção do HIV foi em 1988 com a implantação do primeiro Centro de Orientação e Apoio Sorológico (COAS). Em 1997, houve a consolidação da prática de aconselhamento e a mudança do nome COAS para Centro de Testagem e Aconselhamento (CTA). Atualmente, o aconselhamento é uma das prioridades do Programa Nacional de Doenças Sexualmente Transmissíveis e AIDS (PN-DST/AIDS), que tem como meta a incorporação dessa prática nas atividades assistenciais já existentes nos serviços de saúde ${ }^{(3)}$.

O aconselhamento pode ser considerado uma estratégia de prevenção que transcende o âmbito da testagem, configurando-se como uma ação em saúde, que contribui para a formulação de discursos que propõem a reflexão, a superação de dificuldades no enfrentamento dos problemas relacionados às DST/HIV/AIDS e a adoção de medidas preventivas na busca de uma melhor qualidade de vida e, sobretudo, da autonomia do sujeito no processo de prevenção e cuidado. Esses discursos não apenas refletem relações sociais, mas as constroem e posicionam as pessoas de diversas maneiras como sujeitos sociais, sejam estes aconselhadores ou aconselhandos ${ }^{(4-5)}$.

Assim, o aconselhamento consiste em auxiliar na (re)construção do "saber fazer" do outro com vistas ao estabelecimento de uma autonomia em relação à prevenção do HIV/AIDS, pautado em uma relação dialógica entre usuários e profissionais do serviço que sinaliza a existência de um jogo entre necessidades democraticamente contempladas e modos tecnológicos de agir ${ }^{(6)}$.

Ressalta-se que a prática do aconselhamento não se restringe a uma categoria profissional específica, podendo o profissional que a desempenha se utilizar de concepções teóricas de diferentes campos da ciência, embora se perceba mais comumente a presença implícita ou explícita de teorias da psicologia na sua fundamentação prática.

Entretanto, atualmente, um aspecto percebido na realização do aconselhamento é o fato dessa estratégia estar voltada para os aspectos práticos e para a natureza geral do processo, muitas vezes, sendo conduzido de forma intuitiva, o que evidencia a superficialidade de concepções teóricas que fundamentam as ações e os fenômenos ocorridos.

Destaca-se que o propósito da teoria não é de oferecer explicações universais e amplas previsões acerca do funcionamento da realidade, mas sim o de promover uma compreensão mais abrangente de situações complexas. A capacidade explanatória e explicativa da teoria permite que algumas generalizações possam ser realizadas aumentando a compreensão dos fatos e situações. Entretanto, essa compreensão precisará, inevitavelmente, ser sensível a fatores contextuais e poderá ser redesenhada através das experiências vivenciadas ${ }^{(7)}$.

Ao se considerar o aconselhamento como um momento de troca de informações e interações de sentimentos entre o aconselhador e aconselhando, assim também como uma reflexão sobre a demanda do sujeito aconselhado, este estudo justificou-se pela necessidade do profissional que realiza o aconselhamento possuir um embasamento científico, ou seja, utilizar uma teoria como base filosófica que possa direcionar as suas ações diante da sua realização prática, sendo essa de grande importância para tornar o aconselhamento uma prática mais fundamentada, coerente e consistente.

Desta forma, defende-se a necessidade do aconselhador nortear sua prática, tendo por base algum princípio teórico em relação ao aconselhamento, tornando seu saber/fazer fundamentado. Logo, questiona-se: como as teorias de aconseIhamento, englobando sua concepção sobre o ser humano e os seus pressupostos, podem ajudar o aconselhador a pensar na sua posição frente ao aconselhando? O objetivo desta reflexão foi apresentar os principais pressupostos de algumas teorias do aconselhamento psicológico e sua relação com a prática do aconselhamento em HIV/AIDS.

Dentre as teorias que mais se aproximam do Aconselhamento em DST/AIDS, desenvolvido no Brasil, destacam-se a Centrada no Cliente, a Existencial e a Comportamental ${ }^{(8)}$. Por esse motivo, este estudo buscou deter-se a tais teorias, tendo em vista serem essas as correntes teóricas mais amplamente observadas nos estudos que abordam esta prática. Enfatiza-se, porém, a existência de outras teorias que podem ser aplicadas como base para o aconselhamento.

\section{A. Contextualizando as teorias de aconselhamento}

\section{Teoria Centrada no Cliente}

Essa abordagem é produto do trabalho de Carl Rogers e seus colaboradores. Observa-se que várias são as vertentes atuais, provenientes direta ou indiretamente do pensamento de Rogers, com significativos desdobramentos, sobretudo, após a sua morte em 1987. Entretanto, reconhece-se a importância de apresentar a proposta original de Carl Rogers em seu caráter humanista, de respeito pelo ser humano e suas 
potencialidades ${ }^{(9)}$.

Sua teoria é representada por um dos seus postulados básicos que diz: "todo indivíduo existe em um mundo de experiências, continuamente em mudança, do qual ele é o centro"(10). Esse mundo de experiências representa o indivíduo, mundo esse de natureza interna, denominado campo fenomenológico ou experiencial, que só pode ser completamente conhecido pelo próprio sujeito. Os outros podem observá-lo, medir suas reações, fazê-lo registrar seus pensamentos, mas nunca poderão conhecer de maneira completa e detalhada como certa situação é experienciada ou percebida pelo indivíduo ${ }^{(2)}$.

Assim, o indivíduo é o único que tem a potencialidade de saber a dimensão absoluta da dinâmica de seu comportamento e das suas percepções da realidade e, dessa forma, descobrir comportamentos mais apropriados para si, sendo, improvável, segundo essa teoria, ajudarmos de forma integral o sujeito a ajustar-se à sociedade, pois somente ele possui o conhecimento da totalidade de seu comportamento(11).

Partindo do princípio que a filosofia operacional de uma pessoa não é algo fixo e imutável, mas uma organização fluida e em evolução, o orientador trabalha de modo coerente sobre a hipótese de que o indivíduo tem capacidade suficiente para lidar de forma construtiva com todos os aspectos de sua vida que possam, potencialmente, alcançar sua percepção consciente, para, assim, tornar-se capaz de conduzir a si próprio. A função do terapeuta seria assumir, tanto quanto for possível, a estrutura de referência interna do cliente, de forma a perceber o mundo assim como o cliente o vê, deixando de lado, enquanto estiver fazendo isso, todas as percepções a partir da estrutura de referência externa e comunicar algo de sua compreensão empática para o cliente ${ }^{(12)}$.

Os principais conceitos apresentados nesta abordagem são de tendência atualizante e de não-diretividade. Compreendemos a tendência atualizante como um processo que se alimenta da diferença e que impacta o sujeito centrado, trazendo-lhe uma novidade para aquilo que ele pensa ser sua própria imagem (self). O processo terapêutico, facilitador da liberação desta "tendência", muito mais do que um conhecer a si mesmo, diz respeito a uma desconstrução da imagem rígida de si, o que pode ocasionar um estranhamento e uma sensação de vulnerabilidade ${ }^{(13)}$.

Percebe-se, então, que ao mesmo tempo em que há confirmação do self, uma espécie de retrato que o indivíduo tem de si próprio, há também a presença da tendência atualizante que permite, por outro lado, a preservação do organismo, facultando assim, a consonância entre a experiência vivida e a sua simbolização. O surgimento de desacordo entre o seu autoconceito ou self e as suas experiências vividas originam problemas de ajustamento no indivíduo, denominadas incongruências. Tais situações poderão colocar o indivíduo em adversidade entre seu autoconceito e suas experiências, sendo produzido um comportamento desajustado, o que poderá ocasionar nele um abalo no seu próprio autoconceito, afetando a sua personalidade, sendo esse um dos conceitos chaves da teoria. Assim, o self é visto como um regulador do comportamento, uma vez que o indivíduo se comporta de maneira coerente com seu autoconceito ${ }^{(8)}$.

O conceito de não-diretividade passa, segundo Rogers, pelo acreditar que "o indivíduo tem dentro de si amplos recursos para autocompreensão, para alterar seu autoconceito, suas atitudes e seu comportamento autodirigido"(14). Portanto, Rogers acredita na autonomia do indivíduo, no seu direito de escolher qual a direção a tomar no seu comportamento, bem como, na sua responsabilidade pelo mesmo.

Verifica-se, assim, que os postulados da teoria centrada no cliente seguem um modelo "se-então", que abrangem três partes principais: condições, processo e resultados. Os resultados esperados, em termos dos objetivos do aconselhamento, seria o seu funcionamento como pessoa completa, envolvendo o desenvolvimento de suas tendências atualizantes e a capacidade de realização e de preenchimento de suas necessidades de consideração positiva. Envolvem, ainda, a obtenção de congruência interna, que permita ao cliente autoaceitar-se na sua autenticidade e ser aquilo que realmente $\mathrm{é}^{(2)}$.

\section{Teoria Existencial}

O existencialismo é expresso por uma corrente filosófica que se caracteriza pela preocupação de compreender o homem como ser único, livre e vivente, em busca de um sentido existencial, tendo como principais colaboradores dessa teoria, Rollo May, Van Kaam e Sartre.

O pensamento existencial ressalta a necessidade da tomada de consciência da própria existência, da importância de uma direcionalidade existencial e do livre arbítrio, da aceitação da responsabilidade pela própria existência ${ }^{(2)}$. A frase de Sartre ${ }^{(15)}$ "O homem não é nada mais do que aquilo que ele faz de si próprio", converteu-se em um dos pressupostos básicos do existencialismo.

A abordagem existencialista permite refletir sobre as possibilidades de atuação do aconselhador, a partir de uma concepção histórico-dialética de homem, segundo a qual o sujeito só pode ser compreendido mediante sua história individual e seu contexto sociocultural. Para tanto, tem-se como fundo de sustentação a noção de que o sujeito se faz e é feito por esse conjunto de fatores, sendo possível, por isso mesmo, alterar sua personalidade conforme os acontecimentos que vivencia ${ }^{(15)}$.

Baseado, então, na posição existencialista, o aconselhamento busca localizar o sujeito, isto é, situá-lo no modo como vivencia sua própria história, assim como pretende elucidar o contexto histórico-social em que está inserido e no qual vem constituindo sua personalidade. A partir disso, o sujeito terá condições de compreender como chegou a ser quem é naquele momento e, principalmente, que pode agir de forma a alterar o seu futuro, considerando que os sujeitos se caracterizam, fundamentalmente, pelo que ainda não são e, portanto, pela liberdade de se modificarem e modificarem o curso de suas vidas ${ }^{(16)}$. O aconselhamento se configura, assim, como uma atitude perante o ser humano, no sentido de entendê-lo nas suas experiências individuais, particularmente, aquelas de natureza não-intelectuais e no seu envolvimento total com a situação no mundo em que vive ${ }^{(17)}$.

$\mathrm{O}$ aconselhamento existencial centraliza-se nas 
experiências subjetivas do indivíduo que representam a fonte de todos os seus significados e oferece- Ihe uma ajuda para se reestruturar e se reencontrar, bem como, para o desenvolvimento de novos valores. Em última análise, pode-se definir o aconselhamento como um encontro humano autêntico, no qual o sentido da existência é encontrado pelo sujeito, sendo esse um conceito básico da concepção existencial.

\section{Teoria Comportamental}

A teoria comportamental fundamentada, predominantemente, nas concepções de Skinner, postula a ideia de que o comportamento humano é conceituado como o resultado da ação reforçadora do ambiente, considerando-se que esse ambiente pode ser alterado a fim de que comportamentos adequados sejam mantidos, novos comportamentos eficazes sejam aprendidos e comportamentos inadequados sejam extintos $^{(2)}$. Assim, a principal característica dessa teoria volta-se para o homem como "tábula rasa", que com o surgimento de mudanças específicas no meio em que está inserido, pode modificar certos comportamentos ${ }^{(18)}$.

Dentro da perspectiva comportamental existem dois tipos de comportamento: o conhecido como "comportamento respondente" (denominado assim por responder a um estímulo específico como os comportamentos reflexos, por exemplo) que tem caráter involuntário e o "comportamento operante" que tem caráter voluntário ${ }^{(19)}$.

O comportamento operante é aquele que modifica o ambiente, estando sujeito a alterações a partir das consequências de sua atuação sobre o meio, ou seja, as probabilidades futuras de um operante ocorrer novamente está na dependência das consequências que foram geradas por ele ${ }^{(20)}$.

O condicionamento operante pode ser utilizado através de um procedimento conhecido como modelagem, que consiste na forma progressiva com que o repertório comportamental de um organismo vai sendo modificado através de reforços sistemáticos de comportamentos que se assemelham ao comportamento final ao qual se quer atingir ${ }^{(19)}$.

Portanto, o aconselhamento comportamental é conceituado como uma aprendizagem de comportamentos adaptativos, atuando o aconselhador como auxiliar no processo, de forma que ele irá ajudar o aconselhando a resolver seus problemas, ensinando-o comportamentos ou soluções eficazes.

\section{B. Influência das concepções teórico-filosóficas e seus pressupostos na prática do aconselhador em HIV/AIDS}

A escolha de uma posição teórica possibilita o desenvolvimento do aconselhamento de forma mais aprofundada, não o convertendo a um "bate papo" desimplicado. Logo, a concepção teórico-filosófica na qual o aconselhador se apoia irá de alguma forma direcionar sua prática em aconselhamento.

$\mathrm{O}$ aconselhador que se fundamenta em conceitos da Teoria Centrada na Pessoa implementa atitudes facilitadoras como: a consideração positiva incondicional, ou seja, aceitar o aconselhando do jeito que ele é, sem pré-julgamentos; a compreensão empática do aconselhando, ou seja, a capacidade do aconselhador de compreender a realidade do ponto de vista do indivíduo; e a congruência, atitude em que o aconselhador é coerente com ele próprio e com o aconselhando. Essas atitudes são destinadas a modificação positiva do comportamento do indivíduo, a fim do aconselhando "tornar-se pessoa", um ser humano livre, capaz de encontrar a resolução para as suas dificuldades, realizar escolhas construtivas e de se autocompreender.

O papel do aconselhador centrado no cliente consiste na real percepção das vivências e experiências do aconselhando, a fim de dialogar com o indivíduo sobre suas dificuldades e pontencialidades, e auxiliá-lo a constatar e compreender uma possível atitude "desajustada" nas suas experiências e a correção desse comportamento, seguindo o aconselhando suas tendências atualizantes.

Desta forma, quando o aconselhador não dirige o aconseIhamento com perguntas pré-formuladas, ele possibilita que o cliente fale e se expresse, compreendendo sua realidade e se colocando de forma empática. Logo, a partir da demanda do cliente, ele direciona seu atendimento, tendo como pressuposto que a pessoa aconselhada terá capacidade de desenvolver todas as suas potencialidades de maneira a favorecer sua conservação e enriquecimento, ou seja, capacidade de superar suas crises e conflitos.

$\mathrm{Na}$ teoria existencial, o aconselhador percebe o ser humano como um ser único, livre e vivente, em busca de um sentido existencial. $\mathrm{O}$ aconselhamento é caracterizado pela reflexão profunda da existência do indivíduo na qual ele compartilha com o aconselhador o seu próprio mundo e o aconselhador aceita de forma genuína e incondicional o indivíduo. Portanto, o aconselhador por meio de uma atitude calorosa, proporciona ao aconselhando uma percepção do senso de liberdade do indivíduo; a aceitação de si mesmo, respeitando suas limitações e assumindo um compromisso com ele próprio, levando-o ao encontro de um sentido para sua existência. Seria um aconselhamento no qual o aconselhador iria utilizar recursos para convocar o aconselhando a assumir as responsabilidades de suas ações e escolhas.

Na concepção da teoria comportamental, o homem é caracterizado por comportamentos observáveis, resultantes de reforços ou estímulos vindos do ambiente. No aconselhamento, o aconselhador é responsável por essa introdução de novos estímulos e modificações o ambiente em que o indivíduo está inserido, estruturando e dirigindo a situação e, quando necessário, intervir nesse meio. Assim, o aconselhador visa ajudar o aconseIhando a aprender maneiras eficazes de solucionar os seus problemas, a partir da preparação do ambiente de forma adequada. Isto ocorre, metodicamente, através do ensino ao aconselhando de formas e fórmulas para sua autoproteção. Como exemplo, cita-se o momento em que o aconselhador incentiva o aconselhando a usar o preservativo e ensina-lhe as etapas de sua utilização como forma de proteção das DST e Aids.

Reconhece-se a complexidade do aconselhamento em HIV/AIDS no qual diversos discursos podem existir dentro de uma mesma estratégia, conjugando modos informais e regulatórios, liberadores e disciplinares. Isso significa que a norma e o diálogo podem servir, ao mesmo tempo, como orientação e auxílio para um processo de autoidentidade e de 
mudanças, em que os sujeitos podem interferir, resistir e negociar com os variados discursos materializados na interação aconselhador-usuário(6).

Aqui pontuou-se algumas abordagens teóricas ou filosóficas que funcionam como bússolas para a prática do aconselhamento em HIV/AIDS. Este estudo não defendeu que o profissional aconselhador deva utilizar esse arsenal teórico de forma fechada, sem contextualização ou como um dogma, apenas apontou alguns caminhos teóricos no sentido do aconselhamento não ser percebido como uma conversa improvisada, sem conceituação teórica e metodológica. Cada profissional poderá utilizar a teoria que mais se aproxime da sua visão de mundo, como também a que irá nortear sua prática clínica em aconselhamento.

\section{REFERÊNCIAS}

1. Scheeffer R. Aconselhamento psicológico: teoria e prática. 7. ed. São Paulo: Atlas; 1987.

2. Scheeffer R. Teorias de Aconselhamento. São Paulo: Atlas; 1983.

3. Ministério da Saúde. Aconselhamento em DST, HIV e AIDS: diretrizes e procedimentos básicos.Brasília, DF: O Ministério; 1999.

4. Fairclough N. Discurso e mudança social. 2. ed. Brasília: UnB; 2008.

5. Fonseca PL, Iriart JAB. Aconselhamento em DST/Aids às gestantes que realizaram o teste anti-HIV na admissão para o parto: os sentidos de uma prática. Interface Comun Saúde Educ 2012;16(41):395-407.

6. Souza VS, Czeresnia D. Demandas e expectativas de usuários de centro de testagem e aconselhamento anti-HIV. Rev Saúde Pública 2010;44(3):441-447.

7. Pupo LR. Aconselhamento em DST/AIDS: uma análise crítica de sua origem histórica e conceitual e de sua fundamentação teórica. São Paulo. Dissertação [Mestrado em Ciências]- Faculdade de medicina da USP; 2007.

8. Araújo CLF, Camargo Júnior KR. Aconselhamento em DST/HIV: repensando conceitos e práticas. Rio de Janeiro: Folha Carioca; 2004.

9. Moreira V. Revisitando as fases da abordagem centrada na pessoa. Estud Psicol (Campinas) 2010;27(4): 537-544.

10. Rogers CR, Kinget GM. Psicoterapia e Relações Humanas: teoria e prática da terapia não-diretiva. 2. ed. Belo
Horizonte: Interlivros; 1977.

11. Burton A. Teorias operacionais da personalidade. Rio de Janeiro: Imago; 1978.

12. Rogers C. Terapia centrada no cliente. São Paulo: Martins Fontes; 1992.

13. Vieira EM, Freire JC. Alteridade e psicologia humanista: uma leitura ética da abordagem centrada na pessoa. Estud Psicol (Campinas) 2006;23(4):425-432.

14. Rogers C. Sobre o Poder Pessoal. 3. ed. São Paulo: Martins Fontes; 1989.

15. Sartre JP. O existencialismo é um humanismo. 2. ed. São Paulo: Vozes; 1987.

16. Sartre JP. O ser e o nada - Ensaio de ontologia fenomenológica. Petrópolis: Vozes; 1997.

17. Patterson $\mathrm{CH}$. Theories of Counseling and Psychotherapy. New York: Harper\&Row; 1966.

18. Miranda KCL, Barroso MGT, Silva LMS, Silva MRF. Reflexões sobre o aconselhamento em HIV/AIDS em uma perspectiva freireana. Rev Bras Enferm 2008;61(6):899-903.

19. Bahls SC, Navolar ABB. Terapia cognitivo-comportamentais: conceitos e pressupostos teóricos. Rev Eletrônica Psicol [periódico na internet] 2004 [acesso em 15 jun 2011];4:1-11. Disponível em: http://www.utp.br/psico. utp.online/site4/terapia_cog.pdf.

20. Skinner BF. Ciência e comportamento humano. 11. ed. São Paulo: Martins Fontes; 2003. 